\title{
Jogos zero-jogador ou: do que falamos quando falamos de jogadores
}

\author{
Staffan Björk \\ Suécia \\ staffan.bjork@gu.se \\ Jesper Juul \\ www.jesperjuul.net \\ Tradução: Roger Seula \\ Universidade Federal do Rio Grande do Sul, Porto Alegre, RS, Brasil \\ rogerseula@gmail.com \\ Revisão de tradução: Breno Maciel \\ Universidade Federal do Rio Grande do Sul, Porto Alegre, RS, Brasil \\ brenomaciel@gmail.com
}

Professor do Department of Computer Science and Engineering, Gothenburg University, Gothenburg,

Associate Professor da Royal Danish Academy of Fine Arts, School of Design, Copenhagen, Denmark

\section{Resumo}

Os jogos precisam de pessoas? Em caso afirmativo, o que faz as pessoas importantes para os jogos? Pode parecer auto-evidente que jogos são artefatos projetados para ser usado pelos jogadores, mas neste artigo vamos discutir a ideia paradoxal de jogos zero-jogador. Não desejamos argumentar contra o estudo de jogadores, mas acreditamos que muitas concepções comuns sobre jogadores são demasiadamente vagas para serem úteis. Baseado na análise de jogos zero-jogador, nós fornecemos cinco subcomponentes para ajudar na compreensão do conceito de jogador. Expressas como perguntas, elas são: Este é um jogador humano? O jogador tem agência? O jogador joga ao longo do tempo? $\mathrm{O}$ jogador parece ter intencionalidade? $\mathrm{O}$ jogador exibe preferências estéticas?

\section{Palavras-chave}

Jogador. Jogo. Agência. Zero-Jogador Game. 


\section{Introdução}

O que é um jogo? As definições mais comuns de jogos contam todas com os jogadores como o componente central. Jogos são descritos como objetos projetados (desenhados por designers ou jogadores) que dão aos jogadores a capacidade de agir intencionalmente para alcançar os objetivos de um jogo (p. ex., ABT, 1970; COSTIKYAN, 1994; KLABBERS 2003; SALEN; ZIMMERMAN, 2004; JUUL, 2005). No entanto, muitas publicações dos últimos anos tentaram argumentar que é impossível falar de jogos como objetos projetados, visto que jogos só existem quando jogados, ou como jogados. Por exemplo:

Regras de jogo podem ser interpretadas e reinterpretadas para fins e significados preferenciais, seletivamente invocadas ou ignoradas, desafiadas ou defendidas, mudadas ou aplicadas de acordo com os objetivos coletivos de diferentes grupos de jogadores. Em suma, os jogadores podem pegar o mesmo jogo e coletivamente fazer dele experiências surpreendentemente diferentes. (HUGHES, 1999, p. 94)

"No entanto, a essência de um jogo está enraizada em sua natureza interativa e não há jogo sem um jogador." (ERMI; MÄYRÄ, 2005).

"Jogos são criados através do ato de gameplay, que dependente de atos do jogador." (CONSALVO, 2009, p. 408).

"O mais importante, um jogo se torna um jogo quando é jogado; até então, ele é apenas um conjunto de regras e adereços de jogo aguardando envolvimento humano." (CALLEJA, 2011).

Se há um argumento excepcionalista sobre jogos, um argumento que justifique jogos como forma estética diferentes do que outras, é que os jogos pertencem aos jogadores - no máximo, jogos pertencem ao designer se ele quiser estabelecer um diálogo com o jogador através do jogo - mas jogar, o performativo, expressivo ato de engajar-se com um jogo, contradiz o próprio significado da autoria em jogos. (SICART, 2011).

Por ora, podemos descrever estas citações como centradas no jogador: eles afirmam que os jogos são produtos das ações do jogador, talvez pela exclusão de serem compreensíveis como objetos projetados. Enquanto isso na superfície pode soar simpático (quem não escolheria um jogador vivo sobre um projeto frio?), uma abordagem centrada no jogador enfrenta o grave problema que os jogadores, ironicamente, não se comportam como deveriam: jogadores não acreditam que eles estejam criando jogos por eles mesmos. Pelo contrário, jogadores comprovadamente discutem o mérito de jogos diferentes e variações de regras (p. ex., BERGSTRÖM, 2010) e até mesmo alegarão a preferência a um jogo 
específico pelas experiências que acham que o jogo lhes proporciona. Se os jogadores pudessem criar suas próprias experiências, independentemente das regras e acessórios de um jogo, eles não passariam tempo discutindo os prós e contras de jogos individuais. 0 perigo da abordagem nominalmente centrada no jogador, então, é que ela tende a minimizar aspectos centrais do comportamento do jogador e potencialmente nos distrai de analisar como e por que os jogadores são aplicados nos méritos de diferentes designs. As citações acima, nominalmente centradas no jogador, aparentemente pintam um quadro incompleto sobre o que é um jogador .

Neste artigo, vamos tentar esclarecer o que "jogador" significa, examinando o que acontece quando nós os removemos da equação. Para chegar lá, iremos analisar o grupo de jogos que paradoxalmente são referidos como jogos zero-jogador. 0 nosso objetivo não é cair em uma armadilha paralela "centrada no jogo", negando que os jogadores importam ou que se valha a pena estudá-los, mas simplesmente para fazer uma pergunta fundamental: o que podemos aprender estudando "jogos" para os quais não se faz necessário o envolvimento humano, e estudando jogos como artefatos desprovidos de envolvimento com o jogador? E o que isso nos diz sobre os jogadores?

\section{Jogos zero-jogador}

Jogos zero-jogadores podem ser divididos em quatro categorias:

a) Jogos setup-only: Jogos para qual o input do jogador só é possível na configuração inicial, após a qual o jogo prossegue por conta própria.

b) Jogos jogados por IA: Jogos onde um código de computador assume o papel de jogadores humanos.

c) Jogos resolvidos: Jogos que são resolvidos através de análise, de tal modo que cada sessão de jogo possível é capturada em uma única descrição atemporal.

d) Jogos hipotéticos: Jogo proposto, porém não-implementado, descrito para examinar uma questão ou jogos que realmente existem e que são, para fins práticos, não jogáveis.

\section{Jogos setup-only}


A Figura 1 mostra o Jogo da Vida de John Conway (GARDNER, 1970), um autômato celular no qual estruturas complexas aparecem a partir de regras aparentemente triviais. Carlisle (2009) introduziu o conceito de jogo zero-jogador ao descrever o Jogo da Vida, afirmando que "uma vez que o tabuleiro foi inicialmente estabelecido, não há intervenção do jogador". 0 jogo é digno de nota por ser equivalente de Turing (pode calcular qualquer coisa que um computador possa) e pelos padrões de auto-montagem que podem ser construídos dentro dele. O Jogo da Vida é provavelmente discutido como um jogo porque os jogadores podem usá-lo para desafiar-se a projetar certos padrões, mas ao mesmo tempo isso contradiz a noção de que um jogo é algo que alguém joga.

Figura 1: Jogo da Vida de Conway.

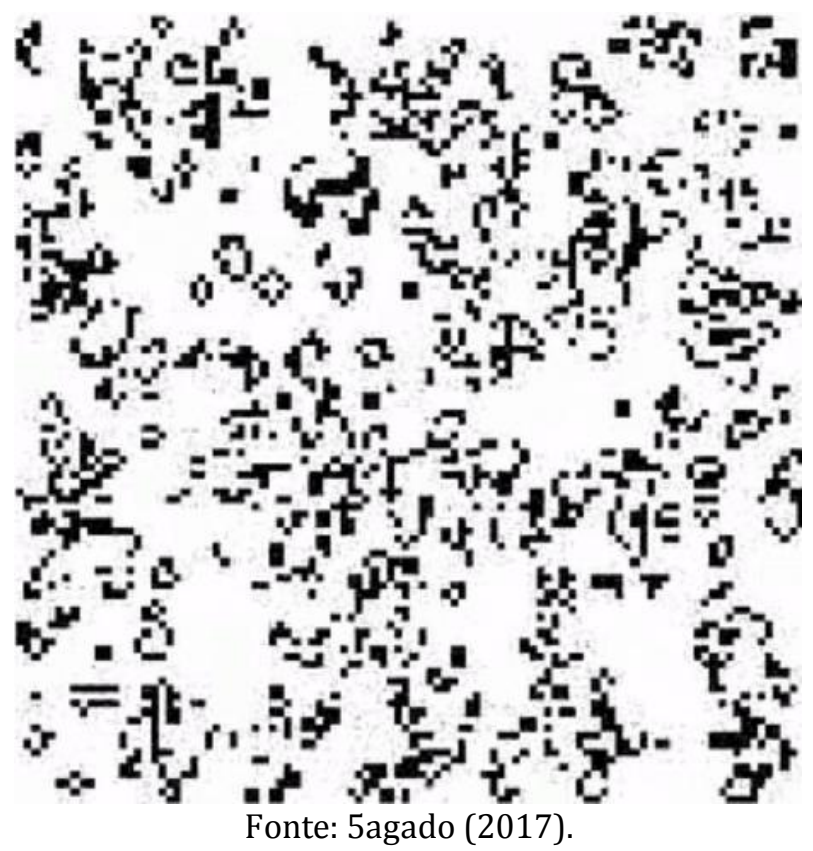

Jogos de programação é um subgrupo de jogos setup-only, onde as pessoas criam jogadores de IA que competem uns contra os outros nos jogos reais. Desenvolvido pela primeira vez na década de 1970, o RobotWar é um exemplo desse tipo de jogo e foi copiado em jogos muito parecidos como Crobots e RoboCode; eles diferem principalmente em qual linguagem de programação é usada (ver EDMUNDS, 1981 para uma descrição da primeira versão comercial da RobotWar). Todos esses jogos permitem que os jogadores escrevam códigos que descrevam o comportamento de um robô e então deixem esses robôs competirem uns contra os outros em combate. No entanto, os jogos de programação não são os primeiros jogos em que as pessoas podem criar regras para o comportamento do jogador. 
Axelrod (1984) descreve os torneios no jogo Iterated Prisoner's Dilema, para o qual as pessoas enviam algoritmos. Jogadores de IA que não dependem de computadores também foram desenvolvidos para Hex (SHANNON, 1953) e Tic-Tac-Toe (MICHIE, 1961).

Figura 2: The Incredible Machine

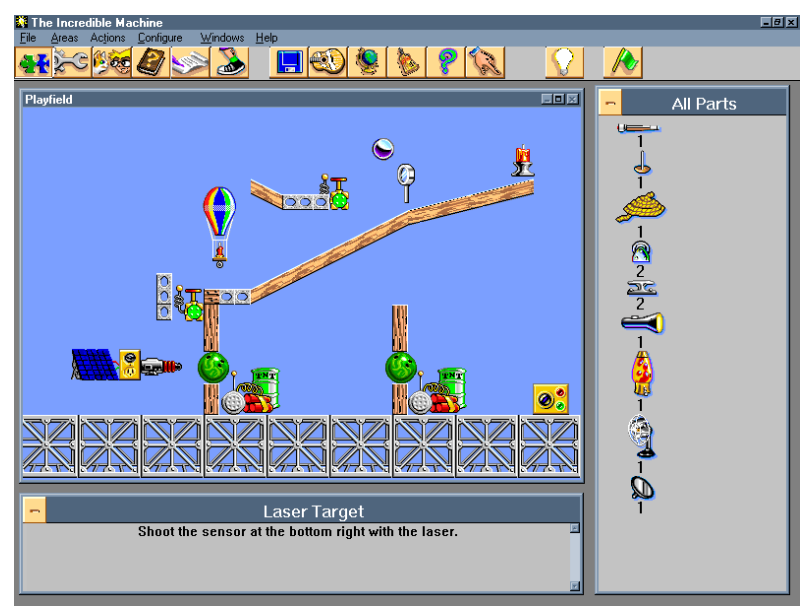

Fonte: Internet Archive (1994) identifier TIMDEMO2.

Outra variação dos jogos setup-only zero-jogador são os jogos comerciais onde os jogadores podem influenciar o jogo ou a configuração do nível, mas não influenciam o gameplay depois de iniciado. A série de jogos de quebra-cabeças Incredible Machine (Figura 2) é um exemplo disso. 0 jogo de tabuleiro Space Alert pode ser visto como um exemplo fraco de um jogo zero-jogador, uma vez que ele tem duas fases principais de gameplay, onde não se permite nenhum comando por parte dos jogadores. No videogame Peggle, o jogador atira uma bola e precisa esperar que ela siga seu curso pelo campo de jogo. Esses exemplos demonstram que muitos, se não a maioria dos jogos, contêm passagens de zero-jogador.

\section{Jogos jogados por IA}

Quando o papel de um jogador humano é tomado por um algoritmo, outro caso de jogos zero-jogador aparece. Assim como um computador pode simular a experiência de um jogo em dupla em jogos para um único jogador, assumindo o papel de um jogador, o jogo individual pode se tornar um jogo zero-jogador quando o computador assume o papel desse um único jogador humano. Exemplos comuns disso incluem jogos como Xadrez e Go, quando estes são executados por jogadores de IA para jogarem uns contra os outros. Na verdade, a 
razão pela qual poucos jogos de computador se qualificam como zero-jogador não é que o gameplay ou a tecnologia o impeçam, mas sim que os usuários não têm a opção de deixar a IA já implementada controlar todas as posições dos jogadores.

\section{Jogos resolvidos}

Grande parte do trabalho em inteligência artificial e teoria dos jogos em jogadores de IA levou ao objetivo de tentar resolver jogos. Por exemplo, foi provado para o jogo de Damas que a jogada perfeita de ambos os jogadores leva a um empate (SCHAEFFER et al., 2007). Da mesma forma, o jogo Hex de Piet Hein, foi resolvido para alguns tamanhos de tabuleiro e, em 1952, John Nash provou a existência geral de uma estratégia vencedora para o jogador inicial (ANSHELEVICH, 2002). Como podemos ver, resolver um jogo significa reduzir todas as possíveis sessões futuras a uma única descrição atemporal. Nesse sentido, resolver um jogo é remover o aspecto temporal do jogo e, como efeito colateral, remover a necessidade de os jogadores explorarem o sistema de jogo, criando efetivamente um jogo zero-jogador.

\section{Jogos hipotéticos}

A Figura 3 mostra o jogo paródico StatBuilder, que segue nominalmente uma progressão de role-playing padrão de melhoria gradual das habilidades dos personagens, mas na prática só pede aos jogadores que pressionem repetidamente o botão central, sem opções disponíveis. Isso requer ação do jogador, mas ao jogador não são oferecidas escolhas. Compare isso com 4 Minutes e 33 Seconds of Uniqueness, nos quais o objetivo do jogo é simplesmente ser a única pessoa no planeta jogando-o por 4 minutos e 33 segundos. Ambos os jogos negam ao jogador o tipo de agência que tomamos como certa nos jogos. É claro que esses dois jogos também são projetados de forma crítica: o primeiro é uma crítica sobre o gameplay repetitivo de jogos multiplayer massivos e role-playing games; enquanto que o segundo questiona o que significa, de fato, jogar jogos. 
Figura 3 - StatBuilder.

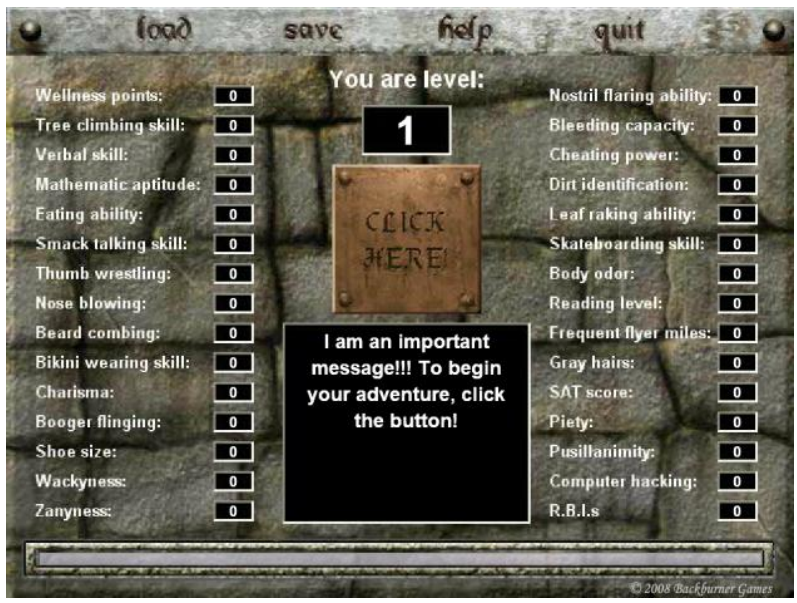

Fonte: Age of Games.net, (s.d).

Ambos são jogos de zero-jogador destinados a serem apreciados mais como artefatos com atividades em potencial do que como atividades reais habilitadas por esses mesmos artefatos. Não se espera investimento de tempo considerável nesses jogos, mas sim que os consideremos como experiências hipotéticas. Compare isso com a idéia de Richard Garfield de "jogos de brinquedo" ${ }^{1}$, jogos que nunca são implementados, mas simplesmente descritos para se considerar uma questão específica. Jogar jogos reais, às vezes, não é tão importante quanto imaginar ou considerar a potencial jogabilidade dos jogos.

Vale a pena notar que outras formas de arte têm obras "hipotéticas" semelhantes, como a literatura "ilegível" em The Making of Americans (1998) de Gertrude Stein, filmes "inassistíveis" como Sleep (1963) de Andy Warhol e música "inescutável" como Metal Machine Music (1975) de Lou Reed. Outro exemplo de jogo seria o Desert Bus (1995). Cada exemplo é, na prática, jogável, legível, assistível ou escutável; mas eles funcionam negando ao usuário uma fonte convencional central de prazer (história progressiva, ritmo e melodia, curva de aprendizado), forçando-nos a encontrar interesse em outro lugar ou em um metanível.

${ }_{1}^{1}$ Descrita na palestra disponível em http://gamecenter.nyu.edu/events/lectureseries. 


\section{O que nos dizem os Jogos zero-jogador}

Voltando às citações iniciais, podemos ver agora que a confusão sobre a relação entre jogos e jogadores, na verdade, deriva de três diferentes conceituações de "jogos":

e) Jogos como atividades potenciais que consistem em interações entre projetos e ações do jogador;

f) Jogos como entidades que só passam a existir quando usadas pelos jogadores;

g) Jogos como artefatos atemporais "resolvidos".

A diferença entre essas três conceituações é, ao mesmo tempo, banal e complexa. A diferença pode ser simplesmente explicada pela distinção entre potencialidade e realidade: uma torre de blocos tem a possibilidade cair se for empurrada, e empurrá-la fará com que ela realmente caia. Um jogo é algo que pode ser potencialmente jogado; às vezes os jogadores vão realmente jogá-los; às vezes os jogadores vão esgotá-los por meio de sua exploração. Embora isso possa ser discutido em termos técnicos, basta dizer que a linguagem cotidiana já lida muito bem com essa questão. Por exemplo, um jogador de StarCraft 2 pode falar sobre StarCraft 2 como um "bom jogo", admirando o intricado equilíbrio entre as unidades Terran, Zerg e Protoss do jogo. Ao jogar o jogo contra um adversário, o mesmo jogador pode encerrar as batalhas com a saudação habitual "gg", também significando "bom jogo", mas referindo-se a essa instância do jogo. Aparentemente, os jogadores não têm problema em distinguir entre StarCraft 2 como um artefato projetado, e StarCraft 2 como ele se desenrola em uma instância concreta de jogo.

Embora jogos diferentes provavelmente proporcionem experiências diferentes, jogar o mesmo jogo várias vezes também pode proporcionar experiências diferentes. Mesmo assim, as diferentes experiências do mesmo jogo geralmente têm similaridades suficientes para os jogadores criarem expectativas para o que as instâncias futuras do jogo trarão e perceberem que elas são mais semelhantes do que as instâncias de jogos derivadas de outros designs de jogos. Isso tem sido descrito como jogos expressando diferentes ideais estéticos (LUNDGREN et al. 2009) em relação ao gameplay. As análises de jogos tipicamente funcionam dessa maneira, descrevendo os jogos como artefatos atemporais e, ao mesmo tempo, assumindo um "jogador modelo" que aceita os objetivos do jogo e conhece as convenções do jogo. Da mesma forma, as pessoas usam suas impressões do gameplay 
potencial de um jogo para discuti-lo: "sugerir um jogo para outra pessoa é simplesmente o ato de combinar a compreensão do gameplay do jogo com a percepção dos ideais estéticos de outra pessoa" (LUNDGREN et al. 2009). Em outras palavras: qualquer concepção de jogadores precisa reconhecer que os jogadores exibem preferências estéticas.

\section{Interação e intencionalidade}

Os jogos de zero-jogador discutidos aqui questionam se as atividades de jogo exigem jogadores. Isso contradiz abertamente os argumentos iniciais centrados no jogador, mas a aparente contradição revela uma camada de nuances: os jogadores de IA, por um lado, substituem os jogadores humanos, mas também é fácil entendê-los como não-jogadores. Uma abordagem para desvendar esse problema é examinar a intuição de que existe alguma maneira pela qual um computador não pode ser um jogador de verdade.

Enquanto interagir com um jogo pode ser visto como uma parte necessária de ser um jogador, isso não significa que seja suficiente. Muitas definições de jogos (p. ex., ABT, 1970; JUUL, 2005; SUITS, 1990; COSTIKYAN, 1994; AVEDON; SUTTON-SMITH, 1971; VON NEUMANN; MORGENSTERN, 1990) apontam que os jogos devem conter ações e escolhas. A menos que os jogadores tenham alguma agência para afetar o resultado de um jogo e possam exercê-lo intencionalmente, eles não são realmente jogadores, ou não estão jogando um jogo.

A ideia da postura intencional (DENNETT, 1989) explica por que podemos ter opiniões diferentes sobre quem ou o que se qualifica como jogadores. 0 argumento de Dennett é que a intencionalidade não é algo inerente aos sujeitos, mas algo atribuído a eles, sejam eles humanos, animais, artefatos ou outros fenômenos. Dennett distingue entre três diferentes posturas que podemos ter em relação a qualquer objeto ou fenômeno: física (proceder de acordo com regras físicas), design (projetado com um propósito), intencional (agindo com um objetivo em mente). De acordo com essa teoria, as pessoas tentam entender umas às outras e a outros fenômenos assumindo uma atitude considerada mais eficiente em relação a quanto trabalho mental ela requer, em comparação com o quão bem ela prevê ações ou eventos futuros. A postura intencional é a postura mais complexa, na medida em que assume que o fenômeno tem objetivos e trabalha ativamente em direção a eles. Essa postura também lida com os fenômenos mais complexos que encontramos - outras pessoas. A postura do design pode lidar com entidades menos complexas através de suposições 
sobre o que aquela entidade é projetada para fazer, enquanto a postura física pode lidar só com os fenômenos que parecem ser governados por um conjunto de regras compreensíveis.

As três diferentes posturas de Dennett fornecem outro benefício para a exploração dos atributos dos jogadores, ou seja, identificam três posturas usadas nas descrições de jogos e jogadores. Enquanto as definições de jogo de Juul e Costikyan afirmam que os jogadores precisam se esforçar e tomar decisões respectivamente, alguém tentando determinar se este é o caso só pode fazê-lo se tomarem posturas intencionais em relação aos jogadores. A definição de jogo de Suits exige engajamento nas atividades, mas, ao contrário de Calleja - que exige envolvimento humano - esse engajamento não precisa necessariamente vir de uma pessoa. Parece haver um consenso geral de que um jogador é aquele em relação ao qual tomamos uma postura intencional.

Pode parecer contra-intuitivo quando a teoria da postura intencional implica que os jogadores não precisam ter intencionalidade real, mas apenas parecer aos outros como tendo isso. No entanto, é consistente com outras teorias usadas para explicar o jogo. Por exemplo, Linderoth (2010) argumenta que a abordagem ecológica da percepção e aprendizagem defendida por Gibson (2000) pode explicar como os jogadores podem atuar com sucesso em jogos. Como essa abordagem, em sua forma geral, não depende da autoconsciência - ela é usada para explicar o comportamento de peixes assim como de pessoas -, uma implicação do argumento é que a intencionalidade não é necessária para explicar o ato de jogar. Enquanto outros podem perceber intencionalidade ou consciência no comportamento de um jogador, a aparência de intencionalidade é um efeito do comportamento, e não a sua causa.

Percebemos que jogadores de IA em versões zero-jogador do Chess e Go como tendo intencionalidade é facilmente argumentado, já que são os mesmos jogadores de IA que precisam jogar contra pessoas - se não pudessem ser interpretados como tentando ganhar um jogo, seriam inúteis como adversários. Da mesma forma, os sistemas desenvolvidos para resolver Hex ou Tic-Tac-Toe precisam ser percebidos como tentativas de ganhar os jogos. Criar jogadores de IA para esses jogos exige, por consequência, que os designers façam com que eles tenham intencionalidade por meio de suas ações, e esse desafio de design é a atividade principal para quem cria jogadores para o jogo Iterated Prisoner's Dilemma e para os jogos de programação iniciados com RobotWar. Curiosamente, os jogos zero-jogador sem interação significativa com jogadores - StatBuilder, 4 Minutes e 33 Seconds of Uniqueness exigem intencionalidade percebida, mas em um meta-nível em que os jogadores, nesses 
casos, também são os iniciadores da instância primária do jogo. 0 Game of Life de Conway difere dos outros exemplos quando a postura intencional é usada para entendê-lo: enquanto os padrões que têm habilidades mais complexas, como a auto-replicação, podem ser interpretados como tendo intencionalidade, também é difícil perceber tais padrões como não-projetados. Esse jogo de zero-jogador pode, portanto, fazer com que os observadores adotem uma postura de design em um meta-nível - assumindo que alguém criou os padrões para propósitos específicos, independentemente de o comportamento do sistema ser interpretado como tendo intenções ou não.

\section{O que significa ser um jogador}

Nossa exploração de jogos zero-jogador foi feita em parte para examinar o que queremos dizer com jogador. Descobrimos que remover temporariamente jogadores da equação nos permitiu identificar um novo nível de nuance para descrever jogos e jogadores, então agora é hora de retornar às questões originais deste artigo: os jogos precisam de pessoas e, em caso afirmativo, o que um jogador traz para um jogo?

o exame acima mostrou que, paradoxalmente, a maioria dos jogos zero-jogador precisa de jogadores que interagem com os jogos e o fazem com intencionalidade percebida. No entanto, esses jogadores não precisam ser humanos para poder cumprir esses requisitos. Embora assistir a jogos zero-jogador como um espectador possa ser recompensador especialmente se alguém criou snippets ${ }^{2}$ de código que controlam um jogador ou está tentando uma nova configuração - alguns desses jogos são mais interessantes como análises críticas sobre o que os jogos são, ou servem chamar a atenção para possíveis estratégias de gameplay. A razão de ser dos jogos hipotéticos não é fornecer experiências de jogo, mas ilustrar pontos sobre jogos para observadores e esses pontos podem, em muitos casos, ser feitos sem que os jogos sejam jogados. Para esses tipos de jogos, os jogadores não precisam ser pessoas reais ou mesmo algoritmos, mas apenas descrições potenciais dos mesmos. Embora isso responda à primeira questão declarada inicialmente no artigo, isso nos leva à pergunta básica: o que exatamente é um jogador?

\footnotetext{
${ }^{2}$ Snippets, em tradução livre, poderiam ser entendidos como "retalhos de código", partes e/ou trechos de código pré-fabricados e parametrizáveis possíveis de serem inseridos em uma aplicação, como jogos digitais.
} 
Ao remover os jogadores, poderíamos, talvez paradoxalmente, mostrar o que foi removido. Ocorre que jogadores têm um número de peculiaridades separáveis, cada uma destacada por um tipo específico de jogo zero-jogador.

a) Jogadores tendo Agência continuada: Jogos setup-only retiram a interação dos jogadores com o estado do jogo pela (talvez) maior parte do tempo que se joga o jogo.

b) Jogadores como seres humanos: Jogadores IA negam a necessidade de jogadores serem humanos.

c) Jogadores como seres temporais: Quando um jogo é resolvido ou quando um jogo é puramente hipotético, não se exige jogadores reais (humano ou não) para jogá-lo. 0 jogador torna-se efetivamente uma ideia atemporal.

d) Jogadores como tendo intencionalidade: Na maioria dos casos e mesmo no caso de jogadores de IA, podemos facilmente identificar um jogador como uma entidade com a intenção de sair-se bem em um jogo. Essa intenção não precisa ser enraizada em um fato psicológico, mas pode simplesmente ser a exposição de uma preferência do sucesso à falha. 0 corolário disso é a existência de spoilsports; entidades que supostamente deveriam ser jogadores, mas que não exibem nenhuma intenção de querer executar o melhor quanto possível em um jogo.

e) Jogadores como tendo preferências estéticas: Temos várias vezes aludido ao fato de que os jogadores tendem a exibir preferências por jogos diferentes. Jogadores reais preferem certas experiências de jogo a outras experiências, comparam jogos e categorizam jogos em gêneros. As concepções de jogos centradas no jogador inicialmente citadas revelam-se, assim, como um tipo específico de jogo zero-jogador, que não refletem o comportamento de jogadores reais, apenas um tipo de jogador hipotético desprovido de preferências estéticas.

Pode-se perguntar se os cinco traços acima descrevem exaustivamente os jogadores. Isto é, seria possível que algo não tivesse nenhum dos traços acima e ainda assim fosse um jogador? 0 trabalho de von Neumann e Morgenstern responde isso através do uso do conceito de jogadores fictícios. Usado para transformar jogos de soma não-zero em jogos de soma zero (para fazer provas matemáticas relativas ao último aplicável ao primeiro), esses 
jogadores não podem interagir com o sistema ou outros jogadores de forma alguma (a participação nos meta-jogos é explicitamente proibida) e não tem qualquer escolha em participar ou não em instâncias específicas de jogo. Enquanto a passividade desses atores e seu uso na prova matemática os nega os quatro primeiros traços, a incapacidade de escolher participar ou não lhes nega a última característica. No entanto, esta incapacidade de não jogar aponta para uma característica não exposta ao olhar para os jogos de zero-jogador até agora: que muitas vezes assumimos que os jogos são atividades voluntárias (como descrito por Huizinga). Não é de se espantar que enquanto os jogos zero-jogador tornaram visíveis alguns traços desconhecidos dos jogadores, nem tudo foi revelado.

Em conclusão, este artigo destacou duas confusões conceituais dentro da pesquisa do jogo. A primeira confusão preocupa-se com a palavra jogo, que é usada tanto para descrever o artefato que apoia e incentiva certa atividade - o jogar - quanto a atividade em si. Essa confusão levou alguns pesquisadores a afirmar que os jogos só existem como atividades realizadas por pessoas. A segunda confusão é relacionada à palavra jogador, e nós apresentamos cinco traços associados aos jogadores, cada qual desafiado por um tipo específico de jogo zero-jogador. Ironicamente, isso nos mostrou que a posição centrada no jogador não é centrada nos jogadores, uma vez que negligencia suas preferências estéticas. A posição chamada centrada no jogador pode soar, em um primeiro momento, como se partisse da perspectiva dos jogadores, mas na verdade, subestima aspectos centrais do comportamento e da experiência do jogador a fim de promover um tipo específico de descrição teórica.

Os game studies precisam ser mais claros sobre nossos conceitos de jogos e jogadores. Ao considerar ambos, jogadores sem a necessidade de jogos e jogos sem a necessidade de jogadores, encontramos problemas com as duas ideias e mostramos que jogadores e jogos dependem uns dos outros de maneiras sutis. No processo, identificamos vários subcomponentes do conceito de jogador. Estes são os detalhes sobre os quais devemos falar quando queremos falar de forma mais precisa e construtiva sobre os jogadores - e jogos.

\section{Referências Bibliográficas}

5AGADO. Conway's Game Of Life in Blender. Towards Data Science, 8 jul. 2017. https://towardsdatascience.com/conways-game-of-life-in-blender-6dd84cd22fa1 
ABT, Clark C. Serious Games. New York, NY: The Viking Press, 1970.

AGE OF GAMES. StatBuilder. http://www.ageofgames.net/en/free-rpg-games/1333-statbuilder.html

ANSHELEVICH, Vadim V. The Game of Hex: The Hierarchical Approach. In Nowakowski, Richard J. (org.). More games of no chance, v. 42, pp. 151-165, Cambridge, UK: Cambridge University Press, 2002.

AVEDON, Elliott M. \& SUTTON-SMITH, Brian. The Study of Games. New York, NY: John Wiley, 1971.

AXELROD, Robert, The Evolution of Cooperation. New York, NY: Basic Books, 1984.

BERGSTRÖM, Karl. The Implicit Rules of Board Games - on the particulars of the lusory agreement. Proceedings of MindTrek 2010, 2010.

CALLEJA, Gordon. In-Game: From Immersion to Incorporation. Cambridge, MA: MIT Press, 2011.

CARLISLE, Rodney P. Encyclopedia of play in today's society, v 1. Thousand Oaks: Sage Publications, 2009.

CONSALVO, Mia. There is no Magic Circle. Games and Culture, v. 4, n. 4, pp. 408-417, 2009. https://doi.org/10.1177\%2F1555412009343575

COSTIKYAN, Greg. "I Have no Words and I Must Design". Interactive Fantasy, In A. RILSTONE (org). Interactive Fantasy \#2, the journal of role-playing and story-making systems, 1994.

DENNETT, Daniel C. The Intentional Stance. Cambridge, MA: MIT Press, 1989.

EDMUNDS, William. RobotWar: A wargame for all programmers, Computer Gaming World. Vol 1, No, 1, pp. 13-17, 1981.

ERMI, Laura e MÄYRÄ, Frans. "Fundamental components of the gameplay experience: Analysing immersion". Proceedings of DiGRA 2005, 2005. http://www.digra.org/wpcontent/uploads/digital-library/06276.41516.pdf

GARDNER, Martin. Mathematical Games - The fantastic combinations of John Conway's new solitaire game 'life'. Scientific American v. 223, pp. 120-123, 1970.

GIBSON, Eleanor J. e PICK, Anne D. An ecological approach to perceptual learning and development. Oxford: Oxford University Press, 2000.

HUGHES, L. A. Children's games and gaming. In SUTTON-SMITH, Brian (org.), Children's Folklore: A Source Book. New York, NY: Routledge, pp. 93-119, 1999. 
JUUL, Jesper. Half-Real: Video Games between Real Rules and Fictional Worlds. Cambridge, MA: MIT Press, 2005.

KLABBERS, Jan H. The gaming landscape: A taxonomy for classifying games and simulations. DIGRA conference 2003, 2003. http://www.digra.org/wp-content/uploads/digitallibrary/05163.55012.pdf

LINDEROTH, Jonas. Why gamers don't learn more - An ecological approach to games as learning environment. Nordic DiGRA 2010, 2010.

LUNDGREN, Sus, BERGSTRÖM, Karl J. e BJÖRK, Staffan. Exploring Aesthetic Ideals of Gameplay. In Proceedings of DiGRA 2009, 2009. http://www.digra.org/wpcontent/uploads/digital-library/09287.58159.pdf

MICHIE, D. Trial and error. In S.A. BARNETT, S.A. e Mclaren, A. (orgs.) Science Survey, part 2, London: Penguin Books, pp. 129-145, 1961.

SALEN, Katie; ZIMMERMAN, Eric. Rules of play: game design fundamentals. Cambridge: MIT Press, 2004.

Schaeffer, Jonathan, Burch, Neil, Björnsson, Yngvi, Kishimoto, Akihiro, Müller, Martin, Lake, Robert, Lu, Paul e Sutphen, Steve. Checkers Is Solved. Science v. 317, n. 5844, pp. 15181522, 2007.

SHANNON, Claude E. Computers and Automata. In Proceedings of the Institute of Radio $\begin{array}{lllllll}\text { Engineers, } & \text { v. } & 41, \quad \text { n. } & 10, & \text { pp. } & 1234-1241, & \end{array}$ http://ieeexplore.ieee.org/stamp/stamp.jsp?tp=\&arnumber $=4051186 \&$ isnumber $=4051180$ SICART, Miguel "Against Procedurality." Game Studies v. 11, n. 3, 2011. http://gamestudies.org/1103/articles/sicart_ap.

STEIN, Gertrude. The Making of Americans. Bern: Peter Lang, 1998.

SUITS, Bernard. Grasshopper: Games, Life, and Utopia. Peterborough: Broadview Press, 1990.

von NEUMANN, John e MORGENSTERN, Oskar. Theory of Games and Economic Behavior. Princeton, NJ: Princeton University Press, 1990.

\section{Referências Ludográficas}

4 Minutes and 33 Seconds of Uniqueness. Petri Purho. Web-based game. 2009.

Crobots. Tom Poindexter. Disponível para várias plataformas digitais. 1985.

Damas. Jogo de Tabuleiro Tradicional, sem data.

Xadrez. Jogo de Tabuleiro Tradicional, formato atual ca. 1475.

Desert Bus. Penn \& Teller. Sega CD. 1995 (inédito). 
Dungeons \& Dragons. Gary Gygax e Dave Arneson. Jogo de RPG de mesa. Primeira edição publicada em 1974.

Everquest. Sony Online Entertainment. Windows. 1999.

Game of Life. John Conway. Disponível para várias plataformas digitais.

Go. Jogo de Tabuleiro Tradicional, ca. 500 BC.

Hex. Parker Brothers, Jogo de Tabuleiro. 1952.

Incredible Machine. Série de jogos de Jeff Tunnell Productions, PC. 1993 (primeiro jogo).

Iterated Prisoner's Dilemma. Disponível para várias plataformas digitais.

Peggle. PopCap Games. Windows. 2007.

RoboCode. Disponível para várias plataformas digitais. 2001.

RobotWar. Muse Software (Apple II version), PLATO and Apple II. 1970s (PLATO), 1981 (Apple II).

Space Alert. Czech Games Edition. Jogo de Tabuleiro. 2008.

StarCraft 2. Blizzard Entertainment. PC. 2010.

StatBuilder. Backburner Games. Flash. 2008.

Tic-Tac-Toe. Jogo de Tabuleiro Tradicional.

\section{Referências Musicais}

REED, Lou. Machine Music. RCA, 1975.

\section{Referências Cinematográficas}

WARHOL, Andy. Sleep. 1963.

\section{Outras Referências}

Internet Archive. The Incredible Machine 2 Demo. Disponível em: https://archive.org/details/TIMDEM02. Acesso em 19 mar. 2019.

\section{Zero-player game - or: what we talk about when we talk about players}

\footnotetext{
Abstract

Do games need people? If so, what is it that makes people important to games? It can seem self-evident that games are artifacts designed to be used by players, but in this paper we will discuss the paradoxical idea of zero-player games. We do not
} 
wish to argue against the study of players, but we believe that many common conceptions of players are too vague to be useful. Based on the examination of zero-player games, we provide five subcomponents to help in the understanding of the player concept. Expressed as questions, these are: Is this a human player? Does the player have agency? Does the player play over time? Does the player appear to have intentionality? Does the player exhibit aesthetic preferences?

\section{Keywords}

Player. Game. Agency. Zero-Player Game. 